\title{
Measure for Measure: Headline versus Core Inflation
}

\section{Daniel L. Thornton}

W hen discussing long-run inflation trends, members of the Federal Open Market Committee (FOMC) have tended to emphasize the "core" measurewhich excludes food and energy prices-over the corresponding headline measure, which does not. It is not that policymakers believe that food and energy prices do not affect economic decisions; they know very well it is headline inflation that matters for household welfare. Rather, as Chairman Bernanke noted in his July 18 monetary policy report to Congress, the emphasis on core measures is motivated by a desire to track and predict persistent inflation: "Food and energy prices tend to be quite volatile, so that, looking forward, core inflation (which excludes food and energy prices) may be a better gauge than overall [headline] inflation of underlying inflation trends."

Despite close, long-run similarities between core and headline inflation, not all measures are created equal. As noted recently in this publication, there has been considerable persistence in the difference between the headline and core inflation measures for the PCE and the CPI.1 For example, from November 2002 to August 2006, average year-over-year headline CPI inflation was 1.04 percentage points higher than for core CPI. Over this same period, average year-over-year headline PCE inflation was 0.70 percentage points higher than for core PCE. This means that, based on the CPI measure, consumers experienced a 4 percent larger decline in purchasing power than the core measure would have indicated. Over the same period, the cumulative decline in purchasing power based on the PCE measure was smaller, 2.7 percent, but still significant. Consequently, even over fairly long periods of time, core inflation measures distort the inflation picture.

If the core measure is misleading as an indicator of changes in purchasing power, can it still be useful? The core measure may indeed be useful to both consumers and policymakers if it does a better job of predicting future headline inflation than the corresponding headline measure does. In recent research comparing core and headline CPI inflation, evidence suggests that core CPI inflation better predicts future headline CPI inflation. For example, if headline CPI inflation is below the corresponding core measure, and the core measure is a better predictor of future headline inflation, one might conclude that headline CPI inflation is likely to increase in the future.

Unfortunately, the same is not true for the PCE measure. Current research indicates that headline PCE inflation is a better predictor of future headline PCE inflation than is core PCE inflation. ${ }^{2}$ Consequently, core PCE inflation appears to provide no useful information about future PCE inflation. It is the case, however, that over sufficiently long periods of time, CPI inflation averages about a half of a percentage point higher than PCE inflation-apparently reflecting a larger bias in the former measure relative to the latter. For this reason, one might think that one could forecast future headline PCE inflation by using the core CPI forecast of headline CPI and simply subtracting a half of a percentage point from the headline CPI forecast. Unfortunately, as is the case with the difference between the headline and core measures of these indices, there is considerable persistence in the difference between the CPI and PCE inflation measures. Hence, the differences between these measures averaged over a period of several years can be considerably larger or smaller than 50 basis points. Because of this, core CPI inflation is unlikely to be useful for forecasting future headline PCE inflation.

The alternative is to consider different measures of "core" inflation and not rely on the measures that exclude simply food and energy prices. There is some evidence, in fact, that alternative measures of core PCE inflation may have superior predictive power for headline PCE inflation. ${ }^{3}$

In any event, although preliminary, current research suggests that policymakers and the public may want to pay more attention to headline PCE inflation and less attention to core PCE inflation.

\footnotetext{
${ }^{1}$ DiCecio, Riccardo "Inflation Disconnect?" Federal Reserve Bank of St. Louis Monetary Trends, July 2007.

${ }^{2}$ See Khettry, N. Neil K. and Mester, Loretta J. "Core Inflation as a Predictor of Total Inflation." Federal Reserve Bank of Philadelphia Research Rap-Special Report. April 26, 2006; and Smith, Julie K. "PCE Inflation and Core Inflation." Unpublished manuscript, Department of Economics and Business, Lafayette College, July 6, 2006.

${ }^{3}$ For example, see Smith (2006).
} 